\title{
Patient and carer perceived barriers to early presentation and diagnosis of lung cancer: a systematic review
}

\author{
Shemana Cassim ${ }^{1 *}$ (D) Lynne Chepulis ${ }^{1}$, Rawiri Keenan², Jacquie Kidd ${ }^{2}$, Melissa Firth ${ }^{1}$ and Ross Lawrenson ${ }^{1,3}$
}

\begin{abstract}
Background: Lung cancer is typically diagnosed at a late stage. Early presentation and detection of lung cancer symptoms is critical to improving survival but can be clinically complicated and as yet a robust screening method for diagnosis is not available in routine practice. Accordingly, the barriers to help-seeking behaviour and diagnosis need to be considered. This review aimed to document the barriers to early presentation and diagnosis of lung cancer, based on patient and carer perspectives.

Methods: A systematic review of databases was performed for original, English language articles discussing qualitative research on patient perceived barriers to early presentation and diagnosis of lung cancer. Three major databases were searched: Scopus, PubMed and EBSCOhost. References cited in the selected studies were searched for further relevant articles.

Results: Fourteen studies met inclusion criteria for review. Barriers were grouped into three categories: healthcare provider and system factors, patient factors and disease factors.

Conclusions: Studies showed that the most frequently reported barriers to early presentation and diagnosis of lung cancer reported by patients and carers related to poor relationships between GPs and patients, a lack of access to services and care for patients, and a lack of awareness of lung cancer symptoms and treatment. Addressing these barriers offers opportunities by which rates of early diagnosis of lung cancer may be improved.
\end{abstract}

Keywords: Barrier to diagnosis, Early presentation, Lung cancer, Cancer care, Primary care, Delay to diagnosis

\section{Background}

Lung cancer is one of the most common causes of death from cancer worldwide [1]. It has been estimated that nearly one in five deaths globally are due to lung cancer, with 1.59 million deaths reported in 2012 (19.4\% of the total). Overall survival rates for lung cancer are poor, with five year survival rates being $10-20 \%$ post diagnosis in most countries including New Zealand, Canada, Australia and Sweden [2-4]. A key reason for poor outcomes in lung cancer survival is the fact that it is typically diagnosed at a late stage when the patient has presented with symptoms. Population based screening for early stage lung cancer using LDCT (low dose

\footnotetext{
* Correspondence: shemana.cassim@waikato.ac.nz

${ }^{1}$ Waikato Medical Research Centre, University of Waikato, Hamilton 3240,

New Zealand

Full list of author information is available at the end of the article
}

computerised tomography) has been shown to be effective in identifying cases at an earlier stage and in reducing lung cancer mortality [5]. However, there is a high cost and a high false positive rate in using LDCT as a screening test [6]. Consequently uptake has been very slow and further research is ongoing in assessing whether there are particular high risk populations where screening for lung cancer can be justified.

An alternate strategy is to focus on the reason for late diagnosis. These can be due to patient factors, system factors and tumour factors [7]. Lung cancer symptoms can be different from person to person, and while most people show at least some early symptoms, some show none $[8,9]$. Moreover, symptoms particular to lung cancer may be subtle and not directly related to the lungs and chest (e.g. tiredness and weight loss are sometimes the presenting symptom) $[8,9]$. Consequently, symptoms

(C) The Author(s). 2019 Open Access This article is distributed under the terms of the Creative Commons Attribution 4.0 International License (http://creativecommons.org/licenses/by/4.0/), which permits unrestricted use, distribution, and 
are often misinterpreted or misattributed by both patients and General Practitioners (GPs). Misinterpretation can be exacerbated by the existence of co-morbidities, which can result in delayed diagnosis or referral [10-14]. Cross-cultural variations across nine countries have shown differences in the delay in reporting symptoms, ranging from 7 days to 6 months [15]. Early recognition of lung cancer symptoms combined with early medical help-seeking behaviour can have the potential to increase survival and decrease mortality from lung cancer [11, 16-18]. However, the proportion of patients who are identified with early stage cancer and receive curative surgery is low, with studies showing a prevalence of between 15 and 20\% [19-22].

In saying this, recent research also points out that, although shortening of diagnostic intervals can result in clinical benefits for some patient groups (e.g. in terms of diagnosis and post-diagnosis cancer management in primary care), for others, it may not necessarily translate to improved outcomes. This can be due to various broader reasons including the symptom signature of lung cancer [9] or the patients' perception of their experience within the healthcare system [23].

Overall, to maximise patient survival from lung cancer, early detection remains an imperative factor, alongside prompt referral. It is therefore necessary to increase the proportion of patients diagnosed with early stage disease. However, numerous studies indicate that there are significant barriers towards help-seeking behaviour and diagnosis. The objective of this systematic review was to explore and document the barriers to early presentation and diagnosis of lung cancer, identified by patients and carers (including those specific to indigenous and ethnic minority groups).

\section{Methods}

\section{Search strategy and selection criteria}

Three major databases, Scopus (1960-2017), PubMed (1945-2017) and EBSCOhost (1888-2017), were searched from 23rd November to 8th December 2017, for papers published in English prior to December, 2017. Text words or keywords used in the search were "lung cancer" and "barrier", "obstacle", "difficult" (difficulty)", "problem", or "diagnos" (diagnosis/diagnostic)" combined with (i.e., AND) "general practi" (general practice/ practitioner)", "primary care", or "family practice". Inclusion criteria for the extraction of articles from the databases were original, qualitative studies, published in peer reviewed journals, and a focus on patient and family or carer perceptions of barriers to early presentation and diagnosis of lung cancer. Accordingly, our exclusion criteria were literature reviews, quantitative analyses, studies focusing solely on prevention (e.g. screening) and a focus only on GP or health care provider perceptions of barriers to lung cancer diagnosis. It should be noted here, that our focus on only qualitative analyses was to identify key themes relating to patient perceived barriers to lung cancer diagnosis. By including quantitative studies in our review, we would have risked being in danger of leaving out important themes voiced by patients themselves, as barriers identified based on quantitative surveys or questionnaires tend to be predetermined. Furthermore, our search did not extend to non-English language studies or grey literature. References cited in the selected studies and any literature reviews with broadly similar search criteria were searched for further relevant articles. Figure 1 shows a flow chart of the process of selecting and including relevant studies for this review according to the PRISMA guidelines [24].

The inclusion of articles published only in peer reviewed journals was our first method of assessing the quality each study reviewed. The quality of each study was also assessed using the CASP checklist for qualitative research [25]. All studies yielded generally strong scores in the domains of validity, results and local relevance or value.

\section{Categorisation of perceived barriers}

Walter et al's [7] model for examining pathways to cancer diagnosis was used as a guide for identifying and grouping barriers to diagnosis in the studies selected. We particularly focused on the "contributing factors" section of the model, which indicates that healthcare provider and system factors, patient factors and disease factors contribute to delays in cancer diagnosis and initiation of treatment. It should be noted, however, that while co-morbidities are listed under patient factors in Walter et al's [7] model, we included them as disease factors in our review due to the nature of symptom presentation particular to lung cancer, as discussed previously.

\section{Data extraction}

The selected articles were reviewed and the following data were extracted and compiled into a table: general information about the article (authors' names, year of publication, and methodology); study location; participant information (participant group, ethnicity, and number of participants); and a brief description of the findings, specifically the barriers to early presentation and diagnosis of lung cancer relating to health care system, patient and disease factors. A number of studies that had multiple participant groups (i.e. patients, family members, GPs and other service providers), explored multiple types of cancer (i.e. lung, prostate, breast and colorectal), used mixed methods (both qualitative and quantitative), and had a primary focus that went beyond identifying barriers to early presentation and diagnosis (e.g. developing an intervention) were included, but noted accordingly. 


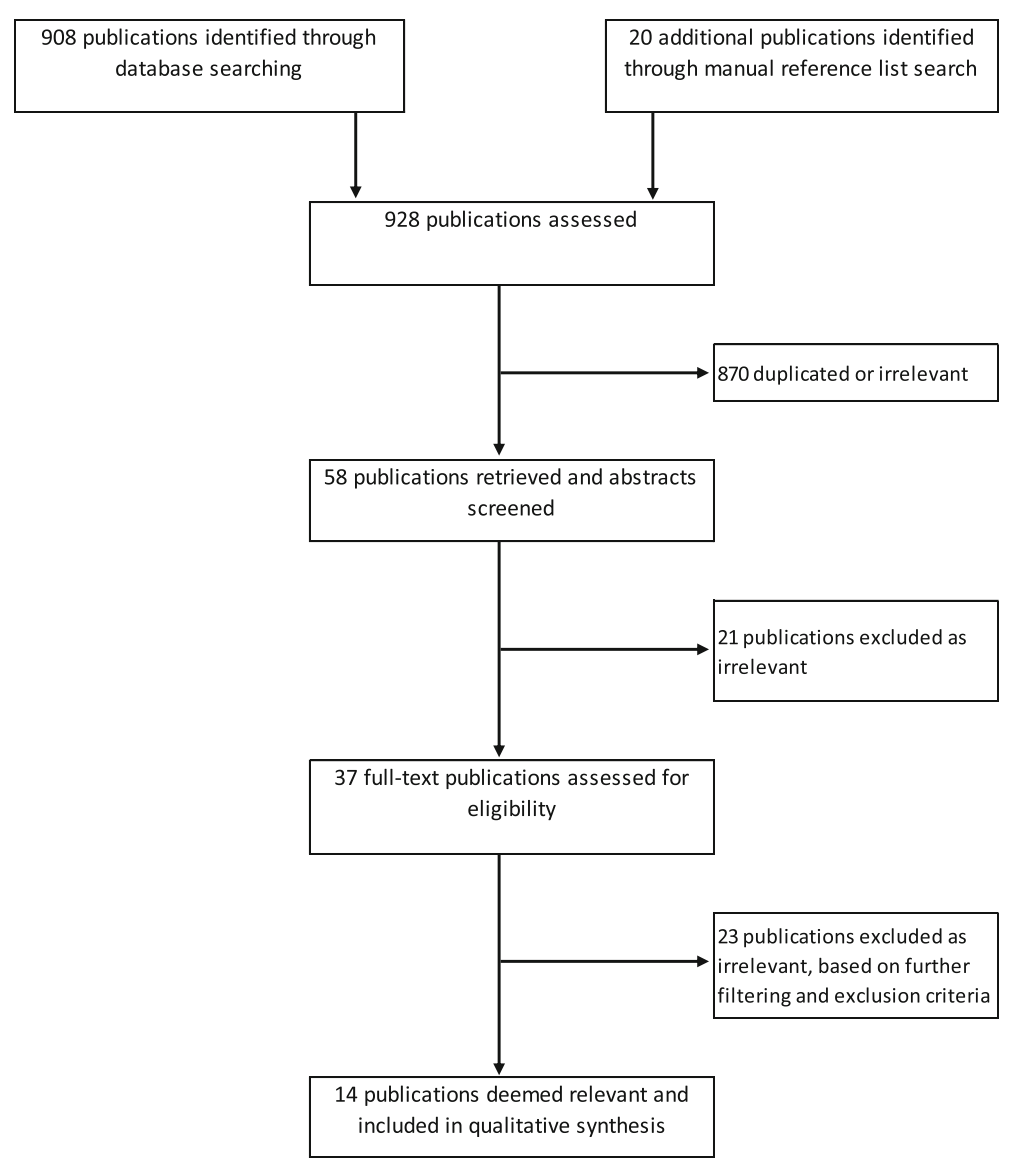

Fig. 1 Process of literature selection for barriers to lung cancer diagnosis flow chart

\section{Results}

We identified 908 publications through our database search, and an additional 20 from a manual reference list search. By screening article titles, 870 were deemed to be duplicates or irrelevant based on topic. The abstracts of the remaining 58 articles were screened, from which 21 were excluded as they examined other cancers, not including lung cancer. Full articles were assessed on the remaining 37 potential publications. Of these, 23 were excluded as they focused on lung cancer screening, they did not examine patient and carer perspectives of barriers to diagnosis and/or they were literature reviews or quantitative analyses. The remaining 14 articles were included in our review. The characteristics and results of the studies are summarised in Table 1.

Six studies were undertaken in the United Kingdom [10-12, 26-28], six in Australia [29-34], one in the United States [35], and one in New Zealand [36]. The ethnicities of the populations studied were European (New Zealand European, "White British", "White"), Māori, Aboriginal and Torres Strait Island peoples, "Black/Black British", "Asian/British Asian", Chinese, "mixed" and other. Seven studies reported that they recruited participants from hospitals, four from community or other support groups, three from General Practices and one from a cancer register.

Five studies included multiple participant groups including patients, family and/or community members, GPs and other service providers [26, 29, 31, 32, 34]. However, as the purpose of this review was to identify barriers to early presentation and diagnosis of lung cancer specifically by patients and families or carers, only the statements made by these participants were included in our analysis. Two studies focused on multiple types of cancer including lung cancer $[27,30]$ - only statements by participants with a lung cancer diagnosis were included in this analysis. One study had a primary focus on the development of an intervention to reduce time to presentation with symptoms of lung cancer alongside barriers to early presentation and diagnosis [26] - the present review considered only the barriers, rather than the intervention discussed in this article. One study included patients with symptoms suggestive of lung cancer, including patients who had not yet received a lung cancer diagnosis and patients post lung cancer diagnosis [10] - this review considered only the barriers specific 


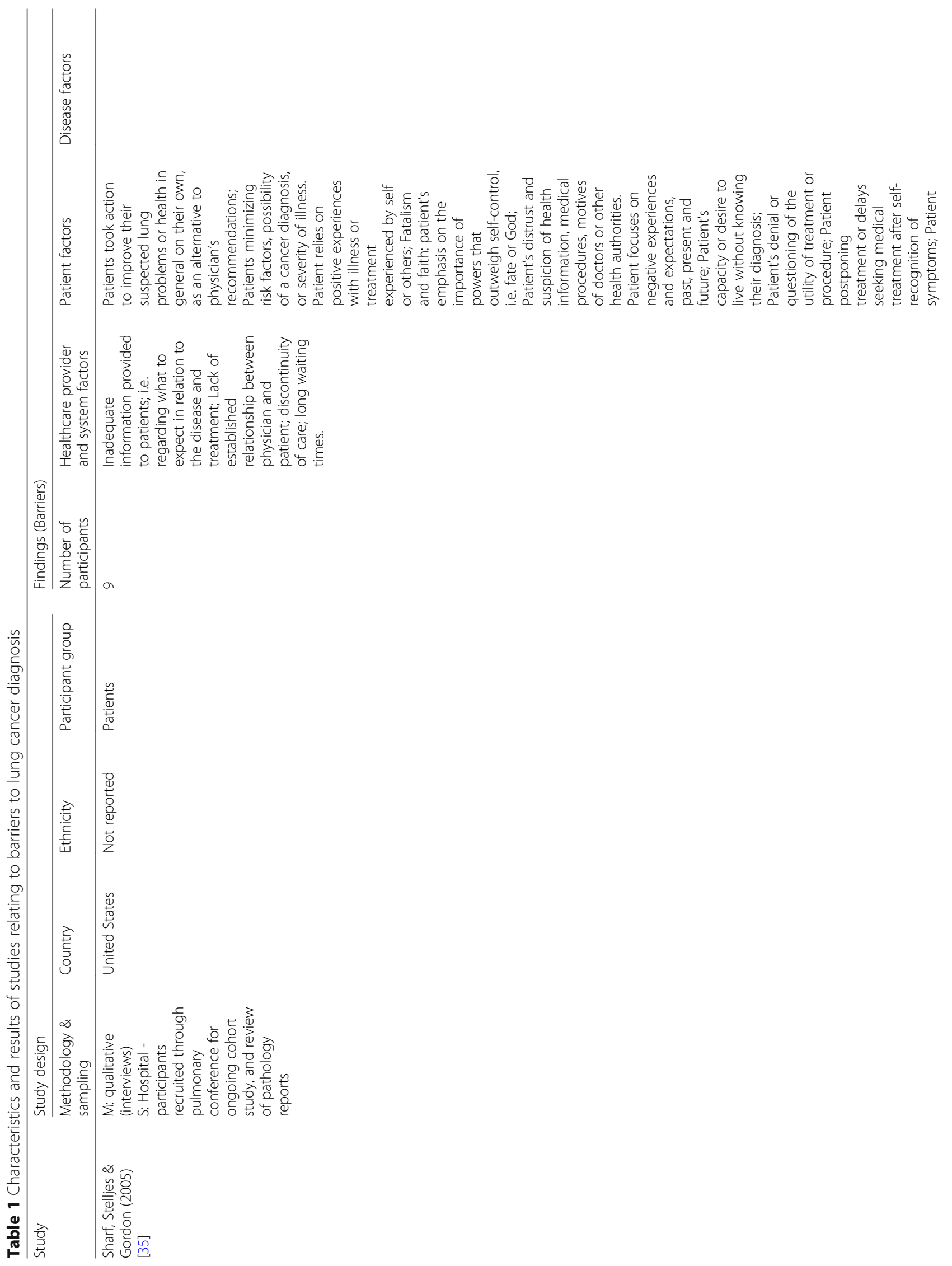




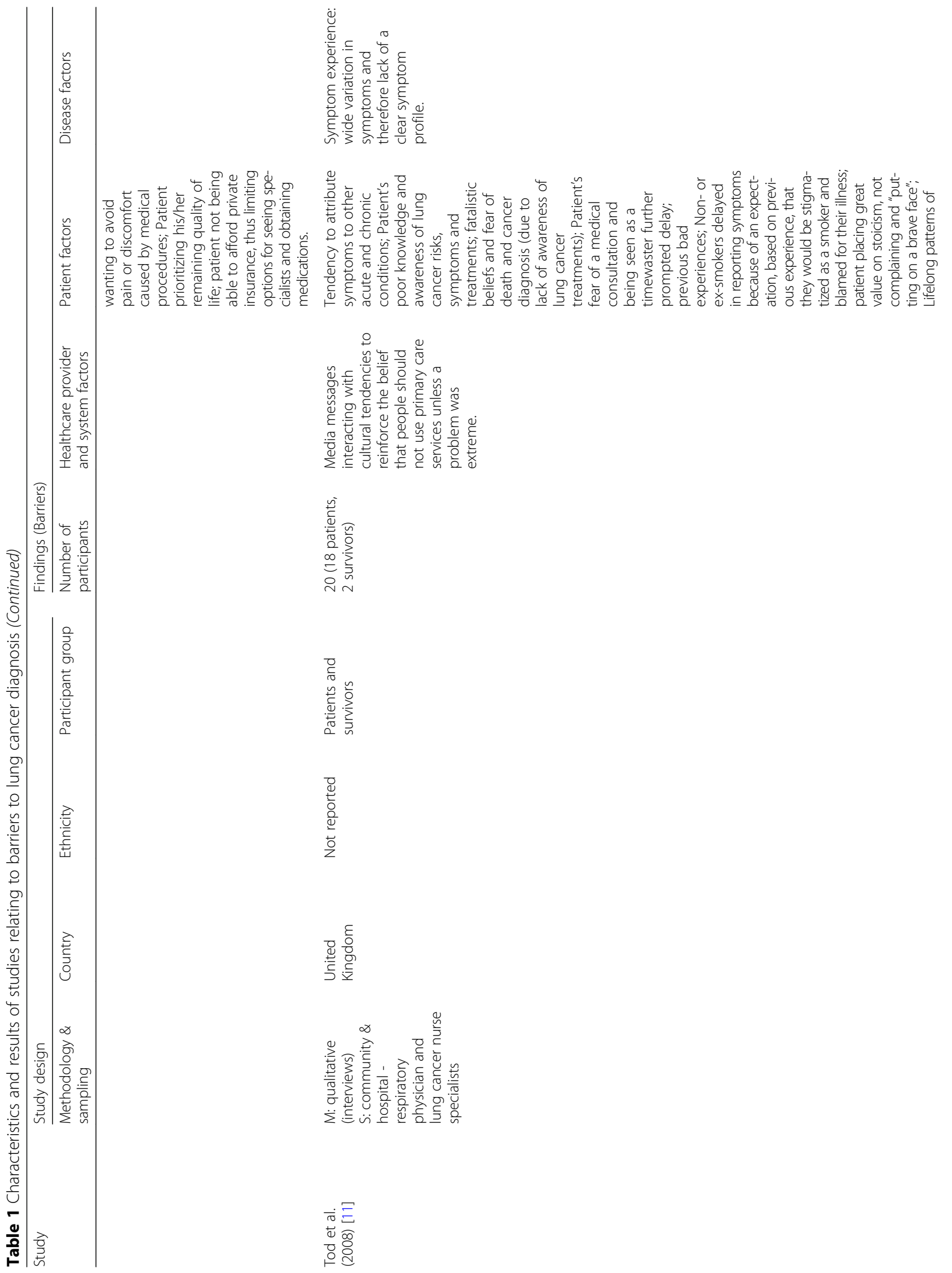




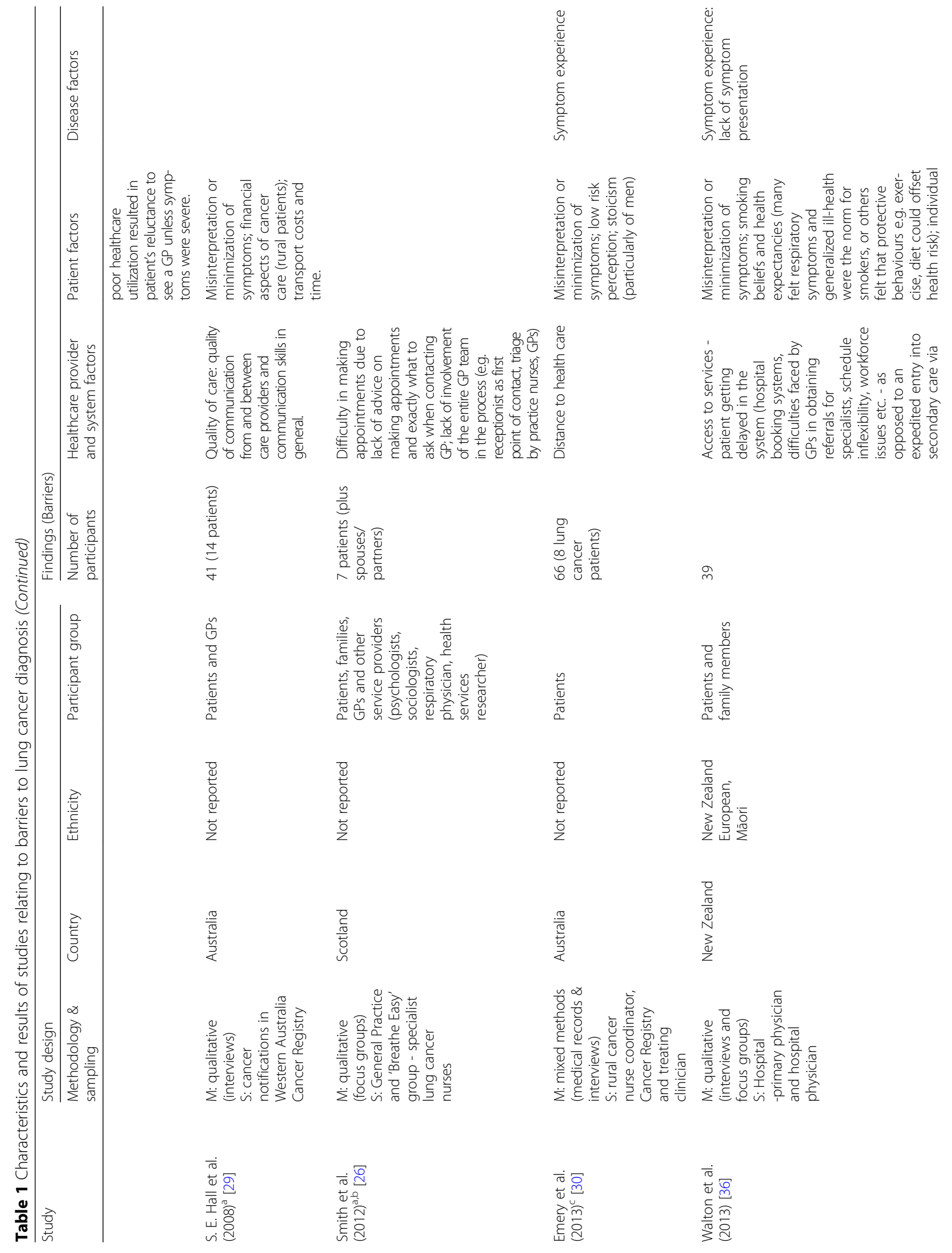




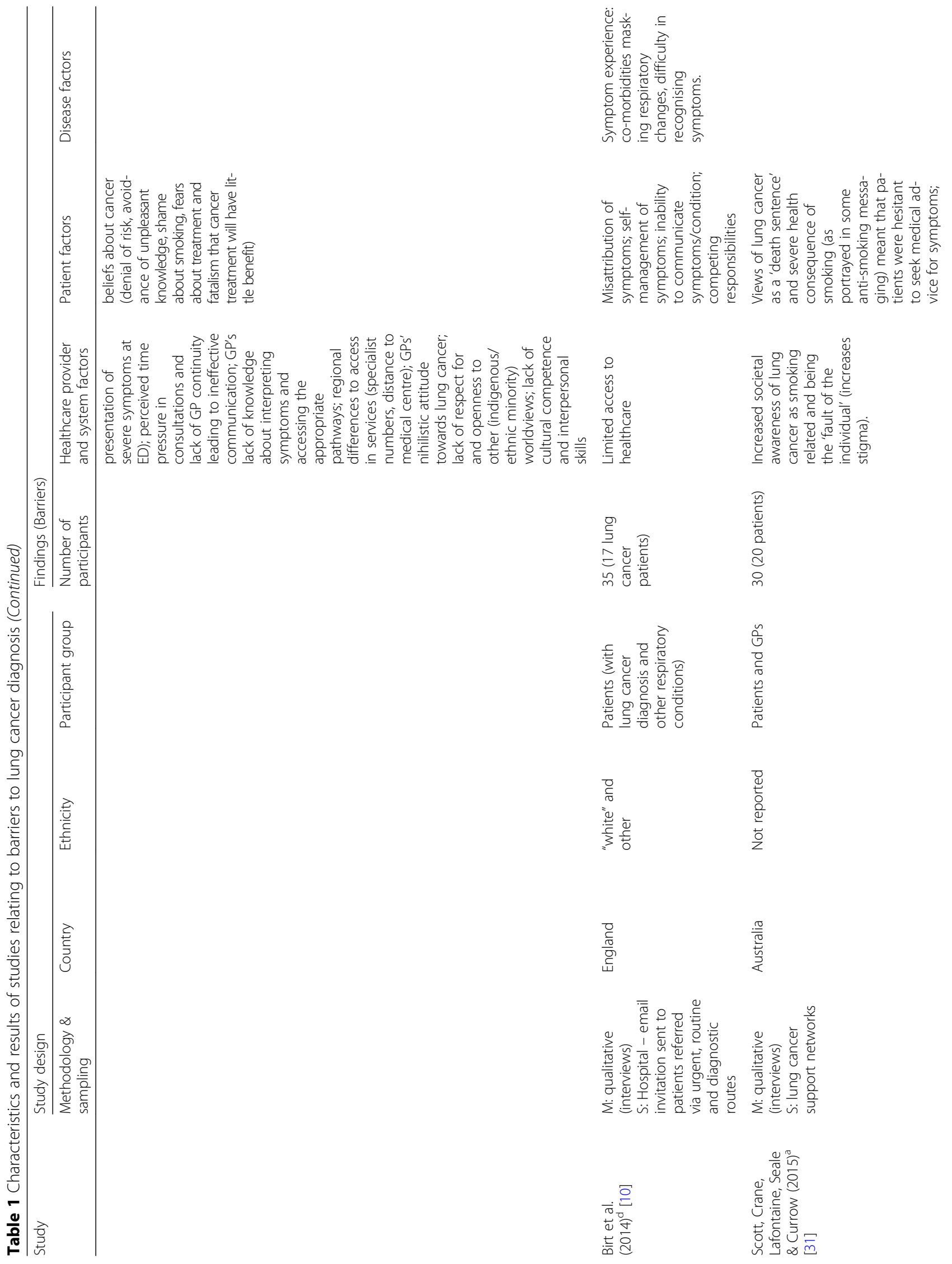




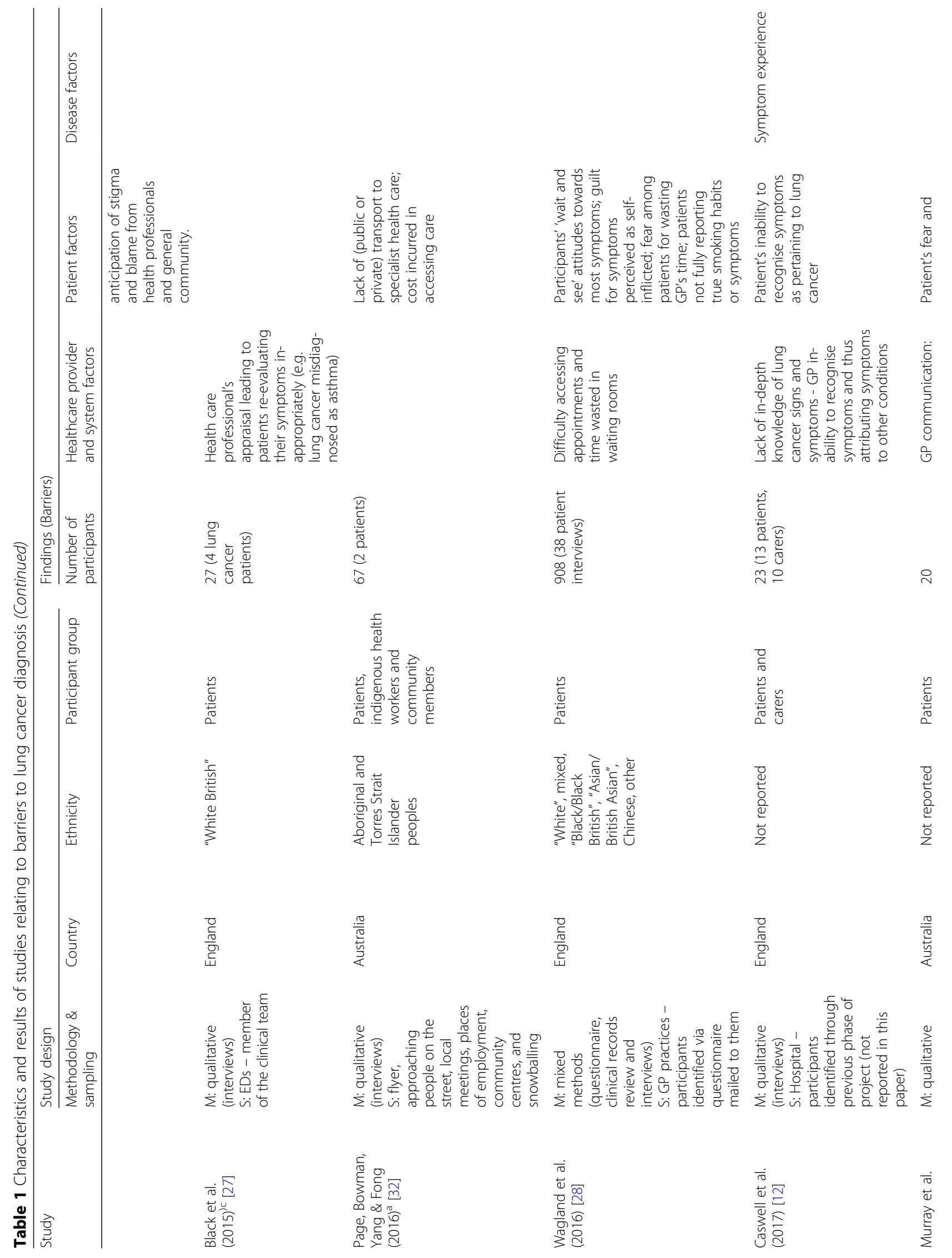




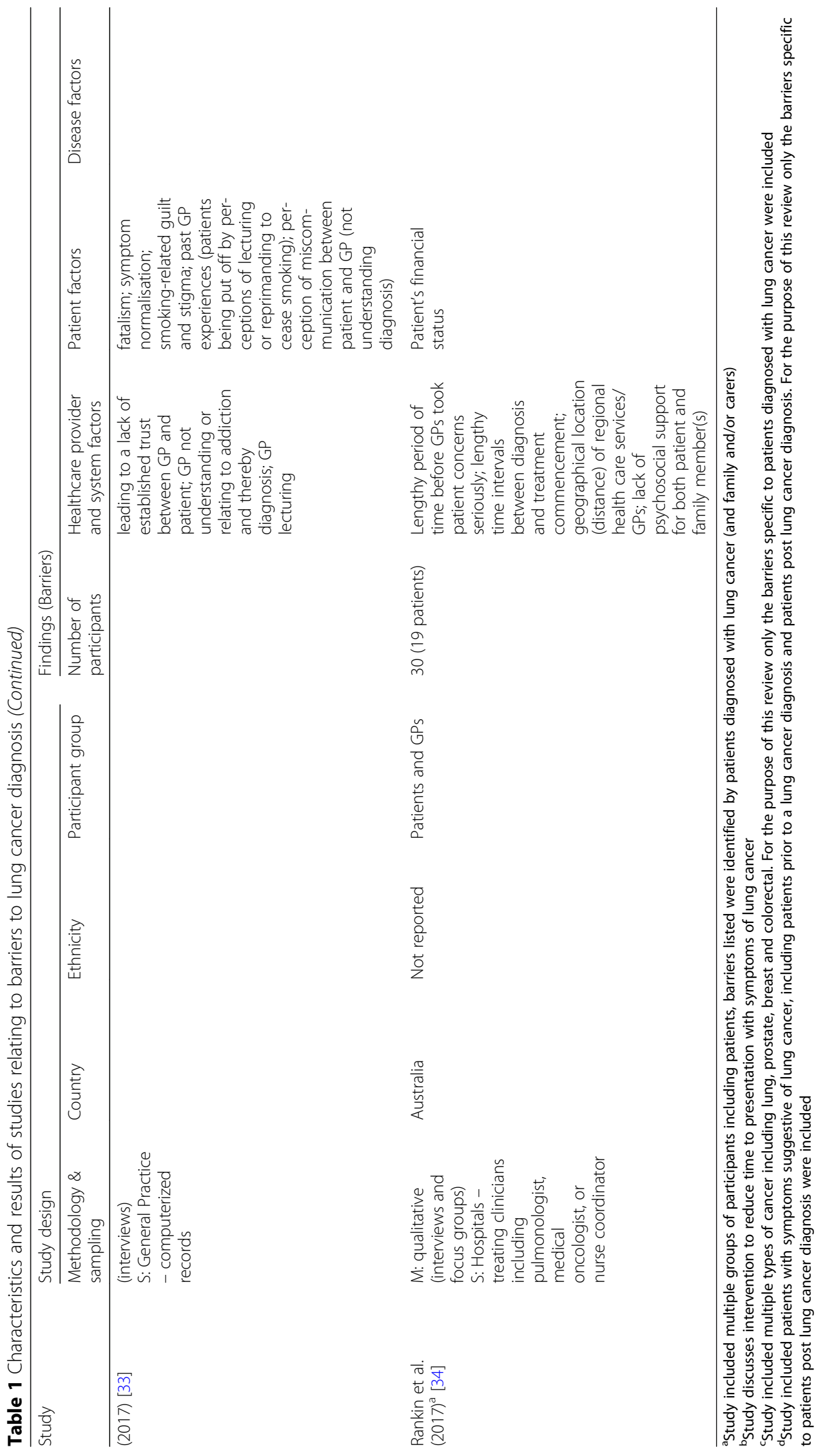


to patients post lung cancer diagnosis. Two studies used mixed methods (both qualitative and quantitative) for data collection [28, 30] - only qualitative data from these studies were considered for the present review. Healthcare provider and system factors as barriers to early presentation and diagnosis were identified in 13 articles, patient factors in 12 and disease factors in five.

The age and gender of participants were reported by most articles. When reported, age was provided either as an age range or mean age. Accordingly, participant age ranged from 39 to 86 years, with mean age ranging from 60 to 79 years. A good gender mix was also included in the studies reviewed.

Our findings were grouped into three categories: healthcare provider and system factors, patient factors and disease factors that serve as barriers to early presentation and diagnosis of lung cancer. These categories were based on the "contributing factors" section of Walter et al's [7] model, as discussed previously. The following sub-sections present our results for each category.

\section{Healthcare provider and system factors}

Healthcare provider and system factors included issues relating to delivery and healthcare policy, and barriers to access. Primarily, the quality of the relationship between GPs and patients was a recurring theme reported in many of the articles. For instance, a lack of an established relationship between patient and GP affected the quality of care provided to the patient. The quality of communication between the patient and GP resulted in a lack of established trust between patient and GP, a lengthy period of time before GPs took the patient's concerns seriously and inadequate information provided to patients [29, 33-36]. Such barriers were also exacerbated by a lack of GP continuity $[35,36]$. Specific barriers identified were, GPs' 'nihilism' towards lung cancer [36], and inability to understand or relate to tobacco addiction [33]. A New Zealand study also reported that a lack of openness to other (indigenous/ ethnic minority) worldviews was a barrier to diagnosis of lung cancer [36].

Broader system factors were also identified as barriers (regardless of country level contexts), including difficulty making or accessing appointments, discontinuity of care (relating to GPs, specialists and/or other healthcare providers), long waiting times, patients getting delayed in the system or difficulty faced by GP to get referrals for specialists [26, 28, 34-36]. Patients additionally observed that limited access to health care (provider and services) was a barrier to diagnosis and care [10, 30, 34, 36].

Patients and carers also stated that GPs had inadequate knowledge of lung cancer symptoms and treatment options available. A number of studies indicated that GPs lacked knowledge about interpreting symptoms and accessing appropriate treatment pathways [12, 36]. According to Black et al. [27], patients indicated that their health care professional's appraisal led to an inaccurate re-evaluation of self-diagnosed symptoms (e.g. symptoms of lung cancer being diagnosed as asthma).

Finally, Scott et al. [31] observed that in Australia, an increased societal awareness of lung cancer as being smoking related and being the 'fault of the individual', increased stigma related to the condition and smoking, thus serving as a barrier to seeking help. Moreover, according to Tod et al. [11] in the United Kingdom, media messages reinforced the fact that people should not use primary care services unless a problem was extreme.

\section{Patient factors}

Patient factors included demographic, psychological, social and cultural factors and previous experience. A key patient related barrier recurrent in the literature was normalisation, misattribution, misinterpretation, minimization or low risk perception of symptoms relating to lung cancer [10-12, 29, 30, 33, 35, 36]. For instance, while many patients felt that respiratory symptoms and generalized ill-health were normal for smokers, others felt that protective behaviours such as exercise or diet could offset health risk. Consequently, patients engaged in self-management of symptoms rather than seeking medical advice $[10,35,36]$.

Fatalistic beliefs and fear of death and/or cancer diagnosis were additionally reported as preventing patients from seeking help, often due to patients' lack of awareness of lung cancer treatments [11, 31, 33, 35, 36]. Patients also indicated that perceived blame, stigma, guilt and shame related to smoking and diagnosis functioned as barriers [11, 28, 31, 33, 36]. Patients were put off visiting healthcare professionals by perceptions that they would be lectured or reprimanded to cease smoking [33]. 'Stoicism' was also reported as a barrier, particularly amongst men, where patients did not wish to complain, instead, putting on a 'brave face' $[11,30]$.

Finally, barriers related to the financial aspects of cancer care, and thus patients' socioeconomic status, such as the high cost of health insurance or treatment and care (e.g. in the United States and Australia), lack of transport to healthcare centre (e.g. in rural Australia) and competing responsibilities (e.g. in the United Kingdom) were identified as barriers to symptom presentation and diagnosis [10, 29, 32, 34, 35].

\section{Disease factors}

Disease factors included site, size and tumour growth rate as well as symptom presentation. Five articles reported disease factors. All of these studies indicated that symptom presentation, specifically, the wide variation in lung cancer symptoms and therefore a lack of a clear symptom profile or a lack of symptom presentation 
overall, made both GP diagnosis and patient awareness difficult $[11,12,30,36]$. For example, Birth et al. (in 2014) [10] reported that the existence of co-morbidities masked many of the symptoms indicative of lung cancer (e.g. pain symptomatic of lung cancer was attributed to a kidney infection based on patient's history of gallstone related pain, cough attributed to patient's existing chronic respiratory symptoms or allergy).

\section{Discussion}

This systematic literature review provided evidence that the reasons for delays in early presentation and diagnosis of lung cancer are complex and multifaceted. It is also clear that all these factors (i.e. healthcare provider and system, patient and disease) overlap. For instance, a key patient and carer perceived barrier relates to the relationship between patients and GPs. Such relationships are crucial to presentation and diagnosis of lung cancer, as they affect the level of trust between GPs and patients, patient attitudes towards their GP and vice versa, and patient perceived blame, stigma, lecturing and reprimanding by GPs [29, 33, 35, 36]. Thus, barriers relating to the relationship between patients and GPs span both healthcare provider and system factors as well as patient factors. Additionally, this review provided evidence that issues relating to access, spanning both healthcare provider and system factors and patient factors, was another key area that posed barriers to patients' help-seeking behaviour [10, 26, 28, 32, 34, 36]. A lack of awareness of lung cancer symptoms and treatment was also identified as a significant barrier. Issues relating to a lack of awareness spanned healthcare provider and system factors, patient factors as well as disease factors, and affected patients, GPs and the general public [11, 12, 27, 31, 32, 36].

There is a clear indication in the research of the pressing need to increase lung cancer awareness, and to provide resources and knowledge regarding symptoms and treatment to patients, healthcare providers and the general public. In particular, research by Tod et al. (2008) [11], included in this review, indicates that some information campaigns relating to lung cancer were seen to contribute to fatalistic views due to a focus on death rather than treatment and/or survival. Since then, however, various awareness campaigns about the early diagnosis and/or detection of lung cancer have been trialled in New Zealand, Australia [37], Scotland [26] and Doncaster, United Kingdom [38], some of which have resulted in an increase in at-risk patients' intentions to see a GP and request a chest X-ray (e.g. [38]). The programme implemented in Doncaster, additionally involved a brief GP education intervention for primary care practices in high lung cancer risk localities, resulting in an increase in chest X-rays and lung cancer diagnosis [38]. In many countries, clinical guidelines and optimal care pathways specific to lung cancer exist, aimed at increasing GP awareness of the disease (e.g. according to the Ministry of Health, New Zealand [39]). While such initiatives are promising, there is a need for replication, rigorous outcome evaluation [40], and to create a multi-pronged approach to raise lung cancer awareness [36]. The findings of this review, as well as that of quantitative, population level studies identifying patient perceived barriers to lung cancer diagnosis, both indicate that an inability to recognize symptoms and the stigma associated with lung cancer posed significant barriers to early diagnosis [41-44]. Thus, there is also a need to provide education to patients about the risks and symptoms of lung cancer, to dispel negative (fatalistic and stigmatising) beliefs about the disease and outcomes, and to empower at-risk patients to get checked in primary care [36]. Such an approach needs to also involve a GP training or education element, as an increase in lung cancer awareness needs to occur in patients, the general public as well as GPs and other healthcare professionals.

Delays within the system were also identified as a major barrier to presentation and diagnosis of lung cancer. For instance, delays in getting appointments, in waiting times, in getting referrals, or getting a diagnosis, the distance and access to health care providers, as well as the financial aspects of cancer care (e.g. cost of treatment, patients' socioeconomic status) hindered access to services, and thus timely diagnosis and treatment [10, 28-30, 34-36]. Similar findings were reported by Sood et al's (2009) [45] review of patients' clinical records identifying barriers to diagnosis of lung cancer. Delay, irrespective of reason, can be frustrating for many patients, and when combined with difficulties accessing information and services, could increase distress [46]. It is clear that a more patient-centred and accessible approach to cancer diagnosis and care is needed.

Furthermore, many studies in our review did not report the ethnicity, or rather the ethnic variation, of their participants [10-12, 26, 29-31, 33-35]. In particular, Sharf et al. (in 2005) [35] and Tod et al. (in 2008) [11] indicated that the fact that their participant bases comprised primarily 'white' patients, rather than 'black' or minority groups, was a limitation of their research. Considering the poorer outcomes relating particularly to ethnic minority and indigenous populations diagnosed with lung cancer [47-52], the findings of this review imply that more qualitative research needs to be conducted and published with a specific focus on ethnic minority and indigenous groups. These findings also hold implications for broader arguments emphasizing the importance of culture, and of acknowledging and respecting diverse worldviews, particularly in cancer care. For example, research from Australia (not included in this review), 
indicates that a lack of cultural competence by GPs was a significant barrier to early presentation and diagnosis of cancer [53-56]. Such conclusions are consistent with the statements of Māori participants in Walton et al's [36] New Zealand study, which indicated that a GP's lack of respect for, and openness to other (indigenous/ethnic minority) worldviews posed a significant barrier to help-seeking behaviour.

Accordingly, the New Zealand Medical Council has made cultural competency training a specific core expectancy in ongoing medical education for doctors and specialty training programmes, partly to address such issues with indigenous communities [57]. In saying this, it is important to recognise that a healthcare professional's cultural understanding of, and engagement with a patient should not be reduced to a simple set of technical skills acquired solely through cultural competency training [58]. Accordingly, the findings of this review reiterate the importance of the need for a focus on building relationships between patient and GP. As such, the Australian studies report that many Aboriginal Australians hold differing health beliefs of cancer causation [53-56]. For instance, this can include a belief that cancer is contagious, or simply the lack of a word for 'cancer', resulting in the diagnosis and its implications not being understood by many of these groups [55]. Accordingly, these researchers indicate that there needs to be an acknowledgement of such differing worldviews by the broader healthcare system, and that GPs need to also be aware of the significance of traditional healing methods germane to each of these communities $[54,56]$. While we acknowledge that not all indigenous communities are the same, there is need for health professionals to have knowledge of, and/or experience in, not only medicine, but also the communities they serve, which goes beyond a simple set of skills acquired through cultural competency training. Overall, more attention needs to be paid to identifying and addressing barriers to early presentation and diagnosis of lung cancer among indigenous communities.

A number of studies in this review also indicated that patients, or potential participants of their research, died prior to the commencement of interviews as a result of lung cancer (e.g. [12, 29, 30]). This was listed as a limitation of such studies. The fact that lung cancer patients passed away within the short timeframe of a recruitment process reinforces the importance and urgency of identifying and addressing the barriers to early presentation and diagnosis of lung cancer.

The strengths of this review were that it assessed 14 high quality studies from respected journals, bringing together statements from a total of 240 patients from five countries and diverse populations. A limitation of this review was that it only examined studies published in
English. However, the consistency of results identified in these studies provides some reassurance as to their validity. Studies reviewed were also from a limited number of countries. Research from countries that are not considered First World nations may have contributed significantly to our findings. Moreover, we documented only the perceived barriers identified by patients and carers. Patients and carers are the most valid source for identifying barriers to early presentation and diagnosis of lung cancer. However, understanding GP views alongside population level data may be necessary in order to introduce effective interventions.

\section{Conclusion}

Early presentation and detection of symptoms relating to lung cancer is critical to improving survival. Delays in early presentation and diagnosis of lung cancer might be avoided if various barriers relating to healthcare provider and system factors as well as patient and disease factors are addressed. This paper provides a complete, exhaustive summary of current patient-centred evidence identifying the existent barriers to early diagnosis of lung cancer, by bringing together and reviewing 14 qualitative studies from various countries. According to the findings of our review, a good starting point to addressing patient and carer perceived barriers, is to focus on the three key areas of relationship building between GP and patient, improving patient access to services and care, and increasing awareness of lung cancer symptoms and treatment, particularly among disadvantaged communities.

\section{Abbreviations}

CASP checklist: Critical Appraisal Skills Programme checklist; GP: General Practitioner; LDCT: Low Dose Computerised Tomography; PRISMA guidelines: Preferred Reporting Items for Systematic Reviews and MetaAnalyses guidelines

\section{Acknowledgements}

Not applicable

\section{Funding}

This work was supported by the Health Research Council of New Zealand [HRC grant number 17/438, entitled 'Improving early access to lung cancer diagnosis for Māori and Rural Communities']. The funding body did not play a role in the design of the study and collection, analysis, and interpretation of data and in writing the manuscript.

Availability of data and materials

All data generated or analysed during this study are included in this published article.

\section{Authors' contributions}

SC: Design of study, acquisition of data, interpretation of data, manuscript writing and revision; LC: Design of study, interpretation of data, manuscript writing; RK: Original conception of study, manuscript revision; JK: Original conception and design of study, manuscript revision; MF: Original conception of study, manuscript revision; RL: Original conception and design of study, interpretation of data, manuscript revision. All authors read and approved the final manuscript.

Ethics approval and consent to participate Not applicable. 


\section{Consent for publication}

Not applicable.

\section{Competing interests}

The authors declare that they have no competing interests.

\section{Publisher's Note}

Springer Nature remains neutral with regard to jurisdictional claims in published maps and institutional affiliations.

\section{Author details}

'Waikato Medical Research Centre, University of Waikato, Hamilton 3240, New Zealand. ${ }^{2}$ School of Nursing, University of Auckland, Auckland 1023, New Zealand. ${ }^{3}$ Waikato Medical Research Centre, Waikato DHB Campus, Waikato Hospital, Hamilton 3240, New Zealand.

\section{Received: 14 August 2018 Accepted: 2 December 2018}

\section{Published online: 08 January 2019}

\section{References}

1. Ferlay J, Soerjomataram I, Dikshit R, Eser S, Mathers C, Rebelo M, et al. Cancer incidence and mortality worldwide: sources, methods and major patterns in GLOBOCAN 2012. Int J Cancer. 2015;136(5):E359-86.http:// globocan.iarc.fr.

2. Ministry of Health. Cancer: New registrations and deaths 2012. Wellington: Ministry of Health; 2015.

3. Coleman MP, Forman D, Bryant H, Butler J, Rachet B, Maringe C, et al. Cancer survival in Australia, Canada, Denmark, Norway, Sweden, and the UK, 19952007 (the international cancer benchmarking partnership): An analysis of population-based cancer registry data. Lancet. 2011;377(9760):127-38.

4. Allemani C, Matsuda T, Di Carlo V, Harewood R, Matz M, Nikšić M, et al. Global surveillance of trends in cancer survival 2000-14 (CONCORD-3): Analysis of individual records for 37513025 patients diagnosed with one of 18 cancers from 322 population-based registries in 71 countries. Lancet. 2018:391(10125):1023-75

5. National Lung Screening Trial Research Team, Aberle DR, Adams AM, Berg CD, Black WC, Clapp JD, et al. Reduced lung-cancer mortality with low-dose computed tomographic screening. N Engl J Med. 2011;365(5):395-409.

6. Deppermann KM, Hoffmann H, Eberhardt WEE. Benefits and Risks of Lung Cancer Screening. Oncology Research and Treatment. 2014;37(suppl 3):58-66.

7. Walter F, Webster A, Scott S, Emery J. The Andersen Model of Total Patient Delay: A systematic review of its application in cancer diagnosis. J. Health Serv. Res. Policy. 2012;17(2):110-8.

8. Cancer Society of New Zealand. Lung Cancer/ Matepukupuku Pūkahukahu 5th ed. Wellington: Cancer Society of New Zealand Inc; 2014.

9. Koo MM, Hamilton W, Walter FM, Rubin GP, Lyratzopoulos G. Symptom Signatures and Diagnostic Timeliness in Cancer Patients: A Review of Current Evidence. Neoplasia (United States). 2018;20(2):165-74.

10. Birt L, Hall N, Emery J, Banks J, Mills K, Johnson M, et al. Responding to symptoms suggestive of lung cancer: A qualitative interview study. BMJ Open Respir Res. 2014;1(1):e000067.

11. Tod AM, Craven J, Allmark P. Diagnostic delay in lung cancer: A qualitative study. J Adv Nurs. 2008;61(3):336-43.

12. Caswell G, Seymour J, Crosby V, Hussain A, Manderson C, Farnan S, et al Lung cancer diagnosed following an emergency admission: exploring patient and carer perspectives on delay in seeking help. Support Care Cancer. 2017:25(7):2259-66.

13. Lyratzopoulos G, Neal RD, Barbiere JM, Rubin GP, Abel GA. Variation in number of general practitioner consultations before hospital referral for cancer: Findings from the 2010 National Cancer Patient Experience Survey in England. The Lancet Oncology. 2012;13(4):353-65.

14. Mendonca SC, Abel GA, Lyratzopoulos G. Pre-referral GP consultations in patients subsequently diagnosed with rarer cancers: A study of patientreported data. Br J Gen Pract. 2016;66(644):e171-e81.

15. Jensen AR, Mainz J, Overgaard J. Impact of delay on diagnosis and treatment of primary lung cancer. Acta Oncol. 2002;41(2):147-52.

16. Goldberg SW, Mulshine JL, Hagstrom D, Pyenson BS. An actuarial approach to comparing early stage and late stage lung cancer mortality and survival. Popul Health Manag. 2010;13(1):33-46.
17. Hill LLE, Collier G, Gemine RE. A patient perspective: Identifying and understanding the barriers associated with the diagnostic delay of lung cancer. EMJ Respiratory. 2017;5(1):92-8.

18. Chatwin J, Povey A, Kennedy A, Frank T, Firth A, Booton R, et al. The mediation of social influences on smoking cessation and awareness of the early signs of lung cancer. BMC Public Health. 2014;14(1):1043-54.

19. Smith SM, Campbell NC, MacLeod U, Lee AJ, Raja A, Wyke S, et al. Factors contributing to the time taken to consult with symptoms of lung cancer: A cross-sectional study. Thorax. 2009;64(6):523-31.

20. Parsons A, Daley A, Begh R, Aveyard P. Influence of smoking cessation after diagnosis of early stage lung cancer on prognosis: Systematic review of observational studies with meta-analysis. BMJ (Online). 2010;340(7740):251.

21. Health Quality and Safety Commission New Zealand. Atlas of Healthcare Variation: Lung Cancer 2016 [Available from:] https://www.hqsc.govt.nz/ourprogrammes/health-quality-evaluation/projects/atlas-of-healthcare-variation/ lung-cancer/\#[6]. Accessed 7 Mar 2018.

22. Mitchell PLR, Thursfield VJ, Ball DL, Richardson GE, Irving LB, Torn-Broers $Y$, et al. Lung cancer in Victoria: Are we making progress? Med J Aust. 2013; 199(10):674-9.

23. Mendonca SC, Abel GA, Saunders CL, Wardle J, Lyratzopoulos G. Pre-referral general practitioner consultations and subsequent experience of cancer care: Evidence from the English Cancer Patient Experience Survey. Eur. J. Cancer Care. 2016;25(3):478-90.

24. Moher D, Liberati A, Tetzlaff J, Altman DG. The PRISMA Group. Preferred reporting items for systematic reviews and meta-analyses: The PRISMA statement. PLoS Med. 2009;6(7):e1000097.

25. Critical Appraisal Skills Programme. CASP Qualitative Checklist 2018 Available from: https://casp-uk.net/wp-content/uploads/2018/01/CASPQualitative-Checklist-2018.pdf. Accessed 29 May 2018.

26. Smith SM, Murchie P, Devereux G, Johnston M, Lee AJ, Macleod U, et al. Developing a complex intervention to reduce time to presentation with symptoms of lung cancer. Br J Gen Pract. 2012;62(602):e605-e15.

27. Black G, Sheringham J, Spencer-Hughes V, Ridge M, Lyons M, Williams C, et al. Patients' experiences of cancer diagnosis as a result of an emergency presentation: A qualitative study. PLoS ONE. 2015;10(8):e0135027. https://doi. org/10.1371/journal.pone.0135027.

28. Wagland R, Brindle L, Ewings S, James E, Moore M, Rivas C, et al. Promoting help-seeking in response to symptoms amongst primary care patients at high risk of lung cancer: A mixed method study. PLoS ONE. 2016;11(11):e0165677.

29. Hall SE, Holman CDAJ, Threlfall T, Sheiner H, Phillips M, Katriss $P$, et al. Lung cancer: An exploration of patient and general practitioner perspectives on the realities of care in rural Western Australia. Aust J Rural Health. 2008;16(6):355-62.

30. Emery JD, Walter FM, Gray V, Sinclair C, Howting D, Bulsara M, et al. Diagnosing cancer in the bush: A mixed-methods study of symptom appraisal and help-seeking behaviour in people with cancer from rural Western Australia. Fam Pract. 2013;30(3):294-301.

31. Scott $N$, Crane M, Lafontaine M, Seale H, Currow D. Stigma as a barrier to diagnosis of lung cancer: Patient and general practitioner perspectives. Prim Health Care Res Dev. 2015;16(6):618-22.

32. Page BJ, Bowman RV, Yang IA, Fong KM. A survey of lung cancer in rural and remote Aboriginal and Torres Strait Islander communities in Queensland: Health views that impact on early diagnosis and treatment. Intern Med J. 2016:46(2):171-6.

33. Murray SR, Kutzerb Y, Habgood E, Murchie P, Walter FM, Mazzaf D, et al. Reducing barriers to consulting a General Practitioner in patients at increased risk of lung cancer: a qualitative evaluation of the CHEST Australia intervention. Fam Pract. 2017;34(6):740-6.

34. Rankin NM, York S, Stone E, Barnes D, McGregor D, Lai M, et al. Pathways to lung cancer diagnosis: A Qualitative study of patients and general practitioners about diagnostic and pretreatment intervals. Ann. Am. Thorac. Soc. 2017;14(5): 742-53.

35. Sharf BF, Stelljes LA, Gordon HS. 'A little bitty spot and i'm a big man': Patients' perspectives on refusing diagnosis or treatment for lung cancer. Psycho-Oncology. 2005;14(8):636-46.

36. Walton L, McNeill R, Stevens W, Murray M, Lewis C, Aitken D, et al. Patient perceptions of barriers to the early diagnosis of lung cancer and advice for health service improvement. Fam Pract. 2013;30(4):436-44.

37. Murray SR, Murchie P, Campbell N, Walter FM, Mazza D, Habgood E, et al. Protocol for the CHEST Australia trial: A phase II randomised controlled trial of an intervention to reduce time-to-consult with symptoms of lung cancer. BMJ Open. 2015;5(5):e008046. https:/doi.org/10.1136/bmjopen-2015-008046. 
38. Athey VL, Suckling RJ, Tod AM, Walters SJ, Rogers TK. Early diagnosis of lung cancer: Evaluation of a community-based social marketing intervention. Thorax. 2012;67(5):412-7.

39. Ministry of Health. Lung cancer. Suspected Cancer in Primary Care: Guidelines for Investigation, Referral and Reducing Ethnic Disparities. Welington, New Zealand: NZGG; 2009. p. 25-32.

40. Stevens W, Murray M. Barriers to the early diagnosis of lung cancer and recommended best practice solutions, with particular reference to Maori and Pacific peoples. Australasian Epidemiologist. 2010;17(3):11-5.

41. Niksic M, Rachet B, Duffy SW, Quaresma M, Møller H, Forbes LJL. Is cancer survival associated with cancer symptom awareness and barriers to seeking medical help in England? An ecological study. Br J Cancer. 2016;115(7):876-86.

42. Carter-Harris L, Hermann CP, Schreiber J, Weaver MT, Rawl SM. Lung cancer stigma predicts timing of medical help-seeking behavior. Oncol Nurs Forum. 2014:41(3):E203-E10.

43. Walabyeki J, Adamson J, Buckley HL, Sinclair H, Atkin K, Graham H, et al. Experience of, awareness of and help-seeking for potential cancer symptoms in smokers and non-smokers: A cross-sectional study. PLoS ONE. 2017;12(8): e0183647.

44. Bergamo C, Lin JJ, Smith C, Lurslurchachai L, Halm EA, Powell CA, et al, Evaluating beliefs associated with late-stage lung cancer presentation in minorities. J Thorac Oncol. 2013:8(1):12-8.

45. Sood JD, Wong C, Bevan R, Veale A, Sivakumaran P. Delays in the assessment and management of primary lung cancers in South Auckland. N Z Med J. 2009;122(1294):42-50.

46. Risberg T, Sørbye SW, Norum J, Wist EA. Diagnostic delay causes more psychological distress in female than in male cancer patients. Anticancer Res. 1996;16(2):995-1000.

47. Robson B, Purdie G, Cormack D. Unequal Impact II: Māori and Non-Māori Cancer Statistics by Deprivation and Rural-Urban Status, 2002-2006. Wellington: Ministry of Health; 2010.

48. Teng AM, Atkinson J, Disney G, Wilson N, Sarfati D, McLeod M, et al. Ethnic inequalities in cancer incidence and mortality: Census-linked cohort studies with 87 million years of person-time follow-up. BMC Cancer. 2016;16(1):755.

49. Ministry of Health. Cancer patient survival 1994-2011. Wellington: Ministry of Health; 2015.

50. Edwards BK, Noone AM, Mariotto AB, Simard EP, Boscoe FP, Henley SJ, et al. Annual Report to the Nation on the status of cancer, 1975-2010, featuring prevalence of comorbidity and impact on survival among persons with lung, colorectal, breast, or prostate cancer. Cancer. 2014;120(9):1290-314.

51. Moore SP, Antoni S, Colquhoun A, Healy B, Ellison-Loschmann L, Potter JD, et al. Cancer incidence in indigenous people in Australia, New Zealand, Canada, and the USA: A comparative population-based study. Lancet Oncol. 2015;16(15):1483-92.

52. Dachs GU, Currie MJ, McKenzie F, Jeffreys M, Cox B, Foliaki S, et al. Cancer disparities in indigenous Polynesian populations: Mãori, Native Hawaiians, and Pacific people. Lancet Oncol. 2008;9(5):473-84.

53. Shahid S, Teng THK, Bessarab D, Aoun S, Baxi S, Thompson SC. Factors contributing to delayed diagnosis of cancer among Aboriginal people in Australia: A qualitative study. BMJ Open. 2016;6(6):e010909.

54. Koefler S. Is cancer a death sentence for Indigenous Australians? The impact of culture on cancer outcomes. Australian Medical Student Journal. 2012;3(1):35-8.

55. Davidson PM, Jiwa M, DiGiacomo ML, McGrath SJ, Newton PJ, Durey AJ, et al. The experience of lung cancer in Aboriginal and Torres Strait Islander peoples and what it means for policy, service planning and delivery. Aust Health Rev. 2013;37(1):70-8.

56. Dunn J, Garvey G, Valery PC, Ball D, Fong KM, Vinod S, et al. Barriers to lung cancer care: health professionals' perspectives. Support Care Cancer. 2017; 25(2):497-504

57. The Royal New Zealand College of General Practitioners. Continuing Professional Development Programme 2014-2017 2013. Available from: https:/oldgp16.rnzcgp.org.nz/assets/documents/Training-and-Beyond/ MOPS-and-CPD-Online-Programme-2014-2017.pdf. Accessed 1 Mar 2018.

58. Kleinman A, Benson P. Anthropology in the clinic: The problem of cultural competency and how to fix it. PLoS Med. 2006;3(10):1673-6.

\section{Ready to submit your research? Choose BMC and benefit from:}

- fast, convenient online submission

- thorough peer review by experienced researchers in your field

- rapid publication on acceptance

- support for research data, including large and complex data types

- gold Open Access which fosters wider collaboration and increased citations

- maximum visibility for your research: over $100 \mathrm{M}$ website views per year

At BMC, research is always in progress.

Learn more biomedcentral.com/submissions 